\title{
Mapping surface breakages of the 2018 Hualien earthquake by using UAS photogrammetry
}

\author{
Ya-Shien Lin ${ }^{1}$, Ray Y. Chuang ${ }^{1,2, *}$, Jiun-Yee Yen ${ }^{3}$, Yi-Chin Chen ${ }^{4}$, Yu-Ting Kuo ${ }^{5}$, Bo-Lin Wu ${ }^{3}$, \\ Shao-Yi Huang ${ }^{3}$, and Ci-Jian Yang ${ }^{1}$ \\ ${ }^{1}$ Department of Geography, National Taiwan University, Taipei City, Taiwan \\ ${ }^{2}$ Research Center for Future Earth, National Taiwan University, Taipei City, Taiwan \\ ${ }^{3}$ Department of Natural Resources and Environmental Studies, National Dong Hwa University, Hualien County, Taiwan \\ ${ }^{4}$ Department of Geography, National Changhua University of Education, Changhua City, Taiwan \\ ${ }^{5}$ Institute of Earth Sciences, Academia Sinica, Taipei City, Taiwan
}

\section{Article history:}

Received 24 July 2018

Revised 25 October 2018

Accepted 9 December 2018

Keywords:

UAV, Structure from Motion, MultiView Stereo, Orthoimage, Surface ruptures

Citation:

Lin, Y.-S., R. Y. Chuang, J.-Y. Yen, Y.-C. Chen, Y.-T. Kuo, B.-L. Wu, S.-Y. Huang, and C.-J. Yang, 2019: Mapping surface breakages of the 2018 Hualien earthquake by using UAS photogrammetry. Terr. Atmos. Ocean. Sci., 30,351-366, doi: $10.3319 /$ TAO.2018.12.09.02

\begin{abstract}
The distributions and characteristics of coseismic surface ruptures are the key to understand fault behaviors. However, traditional field investigations could be time consuming while toppled buildings and damaged infrastructure may be subject to repairs due to rescue missions and transportation recovery within a few days after the earthquake, leading to urgent needs for rapid, extensive surveys before surface breakages are modified. Therefore, we take advantage of UAS photogrammetry to collect aerial images and to map surface fractures for the $M_{w} 6.4$ Hualien, eastern Taiwan, earthquake on 6 February 2018. The earthquake struck Hualien City and generated dense surface breakages over a distance of $\sim 8 \mathrm{~km}$. Together with control surveys for ground control points by using RTK-GPS, UAS photogrammetry uses the methods of the Structure from Motion and Multi-View Stereo to produce high-resolution orthoimages and digital surface models. Our mapping results show that surface ruptures follow the trace of the Milun fault and northern Linding fault. Mapped surface ruptures are usually in en échelon arrays or distributed fractures rather than a through-going fault. Estimated sinistral offset based on orthoimages is more than $60 \mathrm{~cm}$ in Chihsingtan and decreases toward south. The fault behavior of the 2018 Hualien earthquake shows along-strike variations and is somewhat different from the October 1951 earthquake.
\end{abstract}

\section{INTRODUCTION}

Surface breakages including all kinds of ruptures and cracks generated during earthquakes are key features for understanding coseismic deformation and fault behaviors (e.g., Lazarte et al. 1994; Zachariasen and Sieh 1995). When surface breakages are mapped extensively, it is informative to evaluate if they are fault traces or secondary fractures and to characterize the behaviors of strain partitioning, fault segmentation, and deformation styles such as Riedel shear structures and structural duplexes. However, it is challenging and time consuming to map coseismic surface breakages by traditional field investigations.

With the development of techniques in recent years,

\footnotetext{
* Corresponding author

E-mail: raychuang@ntu.edu.tw
}

unmanned aerial systems (UAS), also known as unmanned aerial vehicles (UAVs) and drones, have wide-ranging, efficient surveying abilities and are getting widely used in the earth science community (Hugenholtz et al. 2012; Watts et al. 2012; Carrivick et al. 2013; Colomina and Molina 2014; Klemas 2015; Pajares 2015). Together with photogrammetric techniques of the Structure from Motion (SfM) and Multi-View Stereo (MVS), which are newly developed in the disciplines of computer sciences and image processing, it is unprecedentedly effective to process aerial images taken by UAS for generating high-resolution orthoimages and digital surface models (DSMs) (Westoby et al. 2012; Fonstad et al. 2013; Carrivick et al. 2013; Tonkin et al. 2014; Smith et al. 2016). In very recent years, UAS and the SfM-MVS technique have been used in earth science studies for landslides (e.g., Niethammer et al. 2012; Lucieer et al. 2014; Saito et al. 
2018), active tectonics (e.g., Bi et al. 2017; Gao et al. 2017; Deffontaines et al. 2018), coastal environment (e.g., Mancini et al. 2013), geologic mapping (e.g., Bemis et al. 2014; Vollgger and Cruden 2016), soil erosion (e.g., d'Oleire-Oltmanns et al. 2012; Smith and Vericat 2015), fluvial processes (e.g., Langhammer and Vacková 2018), volcanos (e.g., Nakano et al. 2014), glaciers (e.g., Ryan et al. 2015), etc.

The $\mathrm{M}_{\mathrm{w}} 6.4$ Hualien earthquake on 6 February 2018 produced dense surface breakages in Hualien City, eastern Taiwan, over a distance of $\sim 8 \mathrm{~km}$. The localities of surface breakages and toppled buildings seem to align along the Milun fault, which generated a M 7.3 earthquake in October 1951 (Hsu 1962) with vertical and left-lateral offsets of $\sim 1.2$ and $2 \mathrm{~m}$, respectively (Hsu 1954). The Milun fault is located at the western edge of the Meilun Tableland (Shyu et al. 2005, 2016) (Fig. 1) and is estimated to generate a maximum $\mathrm{M}_{\mathrm{w}}$ 6.4 earthquake according to the seismic hazard assessment of the Taiwan Earthquake Model (Wang et al. 2016). Therefore, one fundamental question is if the 2018 Hualien earthquake is the recurrent event of the 1951 earthquake on the Milun fault. In other words, it is important to examine if the Milun fault indeed ruptured during the 2018 Hualien earthquake and if the fault behaved exactly the same as in 1951 event.

In this study, we use low-cost UAS with the SfM-MVS technique to map surface breakages of the 2018 Hualien earthquake in order to immediately assess seismic damages over an area of several kilometers. Lots of reported breakages are around downtown Hualien City, and damaged infrastructures are subject to deconstructing and repairing due to rescue missions and transportation recovery within a few days after the earthquake, leading to urgent needs for rapid, extensive surveys in a short time. Thus, we take advantage of the mobility of UAS to take aerial images at low altitudes (30 - $60 \mathrm{~m}$ aboveground), which are suitable for the SfMMVS software to generate high-resolution orthoimages and DSMs. Previous studies (Adams and Friedland 2011; Pajares 2015; Gomez and Purdie 2016) discuss UAS applications for disaster monitoring, humanitarian localization and rescue. So far investigations using UAS after earthquakes are mostly limited to surveying damages of infrastructures and buildings (e.g., Baiocchi et al. 2013; Dominici et al. 2017) and to imagery collection (e.g., Quaritsch et al.2010). Konagai et al. (2016) interpret ground fissures by using UAS at two small areas after the 2016 Kumamoto, Japan, (a)

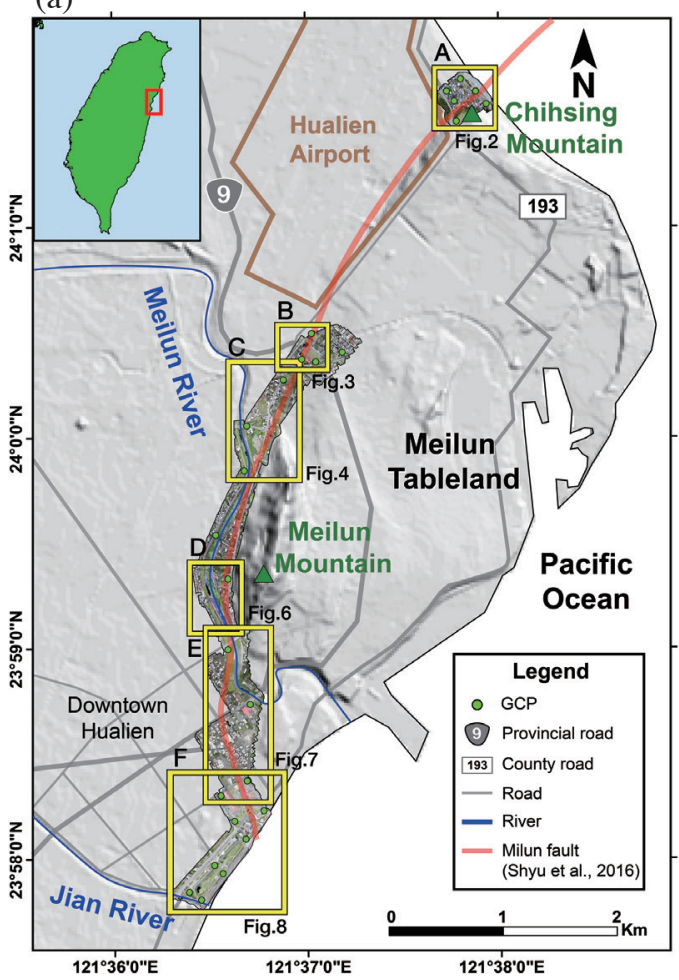

(b)

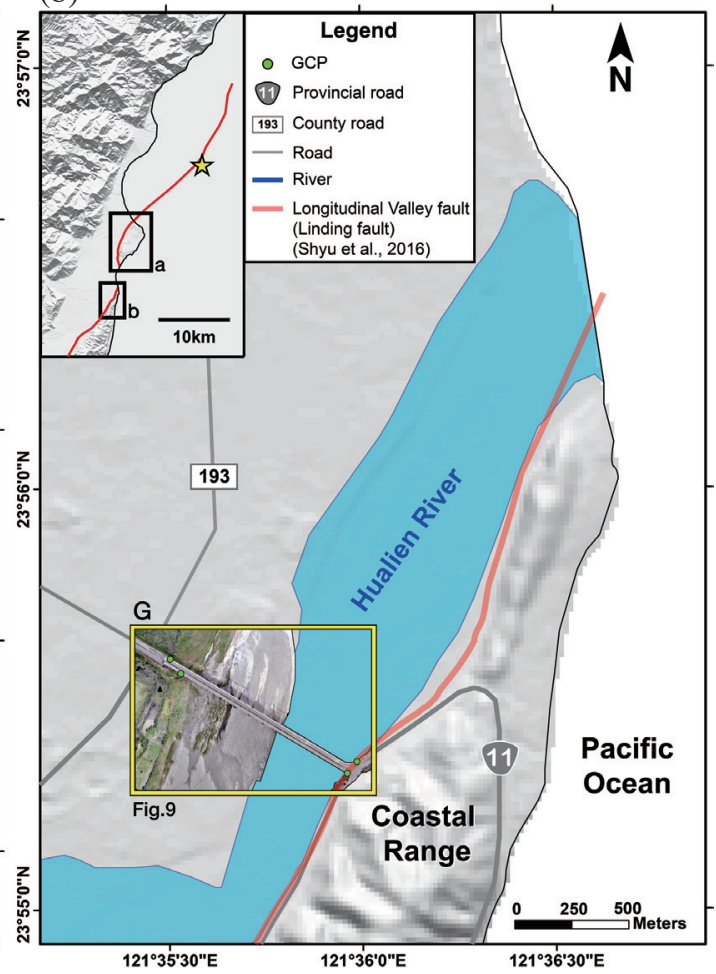

Fig. 1. Areas of UAS surveys for the 2018 Hualien earthquake. Grey lines are major roads and blue lines are main rivers in Hualien area. Green points represent GCPs surveyed by RTK-GPS. Background topography data is 20-m DEM from the Ministry of Interior. (a) UAS orthoimages along the Milun fault. Inset indicates the Hualien area shown in the inset of (b). The red line denotes the surface trace of the Milun fault from Shyu et al. (2016). Yellow boxes indicate six areas discussed in the text. A: Chihshintan, B: IRP, National Dong Hwa University, C: northern Meilun Mountain, D: western Meilun Mountain, E: east of downtown Hualien, and F: southern Hualien City. (b) UAS orthoimages along the northern segment of the Longitudinal Valley fault (Linding fault). The fault trace is based on Shyu et al. (2016). Inset shows two areas of (a) and (b), and yellow star shows the location of the Hualien earthquake mainshock from the Central Weather Burau. Yellow box of G denotes the area of Hualien Bridge discussed in the text. 
earthquake. Yet, there is no extensive UAS-based surveys for surface mapping of coseismic surface breakages. Thus, here we present mapping results of the 2018 Hualien earthquake by integrating UAS and the SfM-MVS technique.

\section{HUALIEN EARTHQUAKE}

The $\mathrm{M}_{\mathrm{w}}$ 6.4 Hualien earthquake occurred at 23:50 local time on 6 February 2018 at about $15 \mathrm{~km}$ north of Hualien City (Fig. 1), following the $\mathrm{M}_{\mathrm{w}} 6.1$ foreshock about few kilometers away from the mainshock epicenter. The earthquake caused 17 fatalities and 285 people injured. By midnight, news and social media have quickly reported damages of roads, bridges, pipelines and buildings from Chihsingtan in the north to downtown Hualien City in the south, including four partially collapsed buildings. Because all these damages were aligned along the western edge of the Meilun Tableland, people quickly paid attention to the Milun fault, which was ruptured in the October 1951 earthquake (Hsu 1954; Bonilla 1975, 1977) and categorized as the first-class active fault (CGS 2012). Therefore, areas along the Milun fault become our target and it is important to investigate surface breakages and evaluate fault behaviors along the areas.

\section{METHODS}

In this study, we use the method of UAS photogrammetry, which includes imagery collection from UAS and image orthorectification by using the SfM-MVS photogrammetric technique. UAS photogrammetry produces orthoimages and DSMs with accuracy of centimeters (Harwin and Lucieer 2012; Hugenholtz et al. 2013; Uysal et al. 2015; Clapuyt et al. 2016; Cook 2017; James et al. 2017). In order to obtain high-resolution results after the Hualien earthquake, our methodology includes three components: (1) aerial image acquisition by UAS, (2) control surveys for ground control points (GCPs), and (3) image orthorectification by the SfM-MVS software. The following sections describe the details of our study procedures and methodology.

\subsection{Flight Plan}

Although UAS provides rapid aerial surveys, it is still challenging to perform UAS flight missions in post-earthquake circumstances. Because repairs of damaged road and dismantlement of collapsed buildings were conducted shortly after the earthquake, we have to give more priority to aerial image collection rather than reconnaissance and control surveys, which means that the UAS procedure for postseismic surveys is different from ones for topographic surveys (e.g., Rusnák et al. 2018).

Therefore, we executed our flight missions as the following steps: (1) Identify target areas and make initial flight plans. We determined the range of each flight mission as well as flight altitude and used software to plan automatic flights. (2) Modify flight plans as we kept receiving information of reported surface damages in the middle of our surveys. Since the early reports have indicated that major damages are along the Milun fault, we immediately divided the areas along the Milun fault into several project ranges. As more information received, we extended our target areas to the Nanbin Park and Hualien Bridge in the south (Fig. 1). (3) Apply flight permission from the Civil Aeronautics Administration, Ministry of Transportation and Communications. Most areas along the Milun fault are within the prohibited zone of the Hualien airport (within $\sim 3 \mathrm{~km}$ radius) so we have to request authorization for flying drones. For such emergent needs for hazardous events, we applied the permission through the National Science and Technology Center for Disaster Reduction. After we received the permission, we were able to execute flight missions except for the area between Chihsingtan and the Innovation and Research Park (IRP), National Dong Hwa University (original National Hualien University of Education), which is inherently banned by our UAS because the distance is too close $(<1 \mathrm{~km})$ to the Hualien Airport (Fig. 1a). (4) Select take-off and landing points. We generally selected some open fields around the center of each project range, which provided clearance for our drones when take-off and landing and allowed us to keep an eye on the drones during the flight missions. (5) Take aerial images by UAS. We mainly take orthogonal images because of limited time. Without oblique images, orthogonal images alone were still sufficient to produce high-quality orthoimages for our mapping. (6) Choose the location of GCPs and measure coordinates. We describe the details of control surveys in section 3.3.

\subsection{UAS and Flight Missions}

We use DJI Phantom 4 Pro and Phantom 2 quadcopters autonomously flown by using the DJI Ground Station Pro software. We executed 20 flight missions in total. Maximum flight time by using one battery is $\sim 30$ minutes, and each mission usually took $1-2$ hrs by using 2 - 4 batteries. In order to take high-resolution images and to avoid potential interference with regular airplanes, we mostly limited flight height below $60 \mathrm{~m}$. Table 1 lists camera parameters of our drones, including focal length, sensor size, and image dimension. We then calculate ground sample distance (GSD) based on the following equation:

$\mathrm{GSD}=H s / f d$

$H$ is flight altitude aboveground, $s$ is sensor size, $f$ is focal length, and $d$ is image dimension. We use Phantom 2 at altitude of $60 \mathrm{~m}$ around the Chihsingtan area so the GSD for this area is $2.36 \mathrm{~cm} \mathrm{pixel}^{-1}$. We use Phantom 4 at the rest areas at altitudes of $30-60 \mathrm{~m}$ and accordingly the GSD is between 
$0.9-1.6 \mathrm{~cm} \mathrm{pixel}^{-1}$. We set front overlap ratio of $80 \%$ and side overlap ratio of $70 \%$. In addition, we set the image capture mode of "capture at equal distance interval" to maintain enough overlap ratio between adjacent aerial images.

\subsection{Control Survey}

In order to achieve precise georeferencing for orthoimages and DSMs, coordinates of GCPs are needed in the SfM-MVS algorithm. Built-in GPS and inertial measurement unit (IMU) devices on the drones provide rough constraints of exterior orientation parameters (camera positions and orientations), helpful for georeferencing without GCPs, also called direct georeferencing (Rizaldy and Firdaus 2012). Without constraints of GCPs, however, constructed DSMs may be distorted (Johnson et al. 2014). Therefore, we conducted control surveys for GCPs across most surveying areas after we collect images by UAS. We examined aerial images and selected 30 well-spread, clear land features as GCPs (Fig. 1), further occupied by Topcon Hiper V dualfrequency RTK-GPS receivers. We measured 5 times at each GCP and used the average value as the resultant coordinates. Typically, the GCPs are at corners of traffic markings, manhole covers, and pavements.

\subsection{SfM-MVS Method}

We use the SfM-MVS software of Bentley ContextCapture to generate orthoimages and 3D models. The SfMMVS algorithm is a novel method to construct topographic models in geosciences (Favalli et al. 2012; James and Robson 2012; Fonstad et al. 2013). As opposed to classic aerial photogrammetry requiring accurate parameters of interior orientations and exterior orientations, the SfM-MVS method is able to construct 3D models and parameters of exterior orientations based on matching features between overlapping images. The SfM-MVS method is highly suitable for aerial images taken by UAS because it is often difficult to obtain accurate interior and exterior orientations of UAS. Common products of the SfM-MVS software are 3D meshes, orthoimages, point clouds, and DSMs. In this study, we mainly use orthoimages for mapping surface breakages. We also use DSMs to evaluate compression features. After we constructed 3D models, we computed the accuracy of orthorectification by using check points (CPs). We use spare GCPs as CPs to evaluate the accuracy.

\section{SURFACE MAPPING BY UAS PHOTOGRAMMETRY}

We mapped surface breakages by using $~ 14000$ aerial images and divided the study areas into 7 domains for discussion (Fig. 1). Orthmosaic images processed by the SfMMVS software provide accurate georeferenced orthoimages to immediately digitize the traces of surface fractures. The evaluation of accuracy by comparing coordinates of CPs measured by RTK-GPS and the orthorectified 3D models is shown in Table 2. Horizontal and vertical errors are basically within $10 \mathrm{~cm}$. We only evaluate two domains because time limitation for the control surveys. We map recognizable surface breakages with compressional, extensional, and strikeslip features. If breakages offset linear land features, then we can distinguish the sense of fracture movement. Note that we map apparent features from our aerial images. For example, we mark a fracture as extension if we see opening along the fracture, although it could be pure strike-slip motion with oblique orientation without any reference landmarks. We mark compression fractures if we observe uplift features, ridges, and bulges. We map breakages as inferred surface fractures if we observe newly tarred or paved surface with traceable linear features in the orthoimages. We mark tensional, compressional, sinistral, dextral, and inferred fractures in red, blue, purple, green, and black, respectively. If fracture width is greater than $10 \mathrm{~cm}$, we then mark the fracture as a thick line (e.g., Fig. 2). In the following sections, we describe mapping results of 7 domains, which are Chihsingtan, IRP National Dong Hwa University, northern Meilun Mountain, western Meilun Mountain, east of downtown Hualien, southern Hualien City, and Hualien Bridge. There may be some other structures around (Yen et al. 2011; Chen et al. 2014); however, neither our surveys nor preliminary field investigations (CGS 2018; ETEC 2018) found strong evidence of coseismic activity of the structures.

\subsection{Chihsingtan}

The northernmost surface ruptures begin from Chihsingtan and are concentrated along the northwestern edge of the Chihsing Mountain and surrounding terraces. Preliminary geologic investigations reported sinistral offset on the gravel beach (CGS 2018; ETEC 2018), which is not recognizable from the aerial images. Our mapped surface breakages generally follow the strike of $\mathrm{N} 60-65^{\circ} \mathrm{E}$ and are distributed densely at the parking lot of the Chihsingtan Tourist Information Center, Chihsing Street, and the southern end of Chihsingtan (Fig. 2), which exactly fit the topographic front of Chihsing Mountain and surrounding terraces. At the parking lot, we mapped a series of parallel N-S striking fractures with sinistral slip and other oblique fractures (Figs. 2b, c, and d), possibly showing synthetic Riedel shears (R) and antitheic Riedel shears (R'). Uneven surface across these fractures shown in orthoimages and DSMs indicate vertical movement, but it is unclear to estimate total dip-slip offset because the vertical motion might be partially associated with slope failures as the fractures broke the coastal revetment, which is right north of the parking lot. Towards southwest, surface fractures show obvious compression along Lane 53 and become minor fractures along 
Table 1. Parameters of UAV models and cameras.

\begin{tabular}{ccccc}
\hline UAV model & Focal length $(\mathbf{m m})$ & Sensor size $(\mathbf{m m})$ & Image dimension & Survey area \\
\hline Phantom 2 & 3.4 & 6.17 & $4608 \times 3456$ & A \\
Phantom 4 Pro & 8.8 & 13.2 & $5742 \times 3648$ & B, C, D, E, F, G \\
\hline
\end{tabular}

Table 2. Accuracy estimates of 3D models at CPs.

\begin{tabular}{cccc}
\hline Survey area & Check Point & 3D horizontal error $(\mathbf{m})$ & 3D vertical error $(\mathbf{m})$ \\
\hline A & CST06 & 0.088 & -0.119 \\
G & L4-1 & 0.012 & 0.013 \\
\hline
\end{tabular}
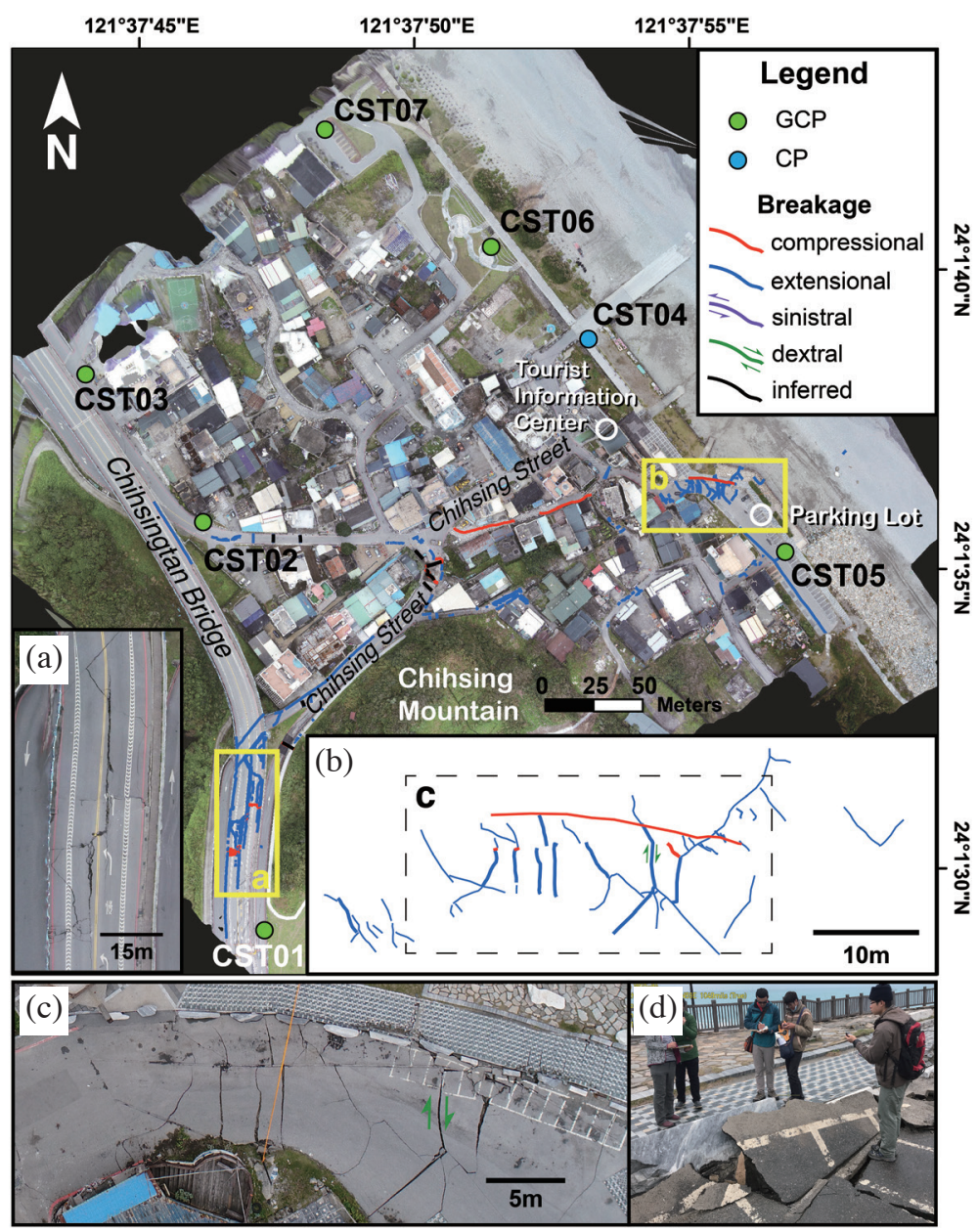

Fig. 2. Mapping of surface breakages in Chihsingtan. Green points are GPCs and blue point is CP. Red, blue, purple, green, and black line denotes compression, extension, sinistral, dextral, and inferred surface breakages, respectively. The principles for mapping breakages are described in the text. (a) Aerial image of surface breakages on the Chihsingtan Bridge. (b) Detailed mapping of surface fractures at the parking lot of the Chihsingtan Tourist Information Center. (c) Aerial image of surface fractures of (b). (d) Field photo showing the compressional feature at the parking lot [the long red line in (b)]. 
Chihsing Street to the south. At Chihsingtan Bridge, distributed fractures are present on the road surface (Fig. 2a).

\subsection{IRP, National Dong Hwa University}

At the IRP, National Dong Hwa University, surface breakages ran across the western campus and bifurcated into two branches of fracture zones. Mapped fractures are more distributed at the northwestern campus and two fracture zones are identified surrounding Hancuei Lake toward south (Fig. 3). One branch ran across Wushou Building and connected to en échelon arrays on running tracks. Fractures south of Wushou Building are along $\sim \mathrm{N} 25^{\circ} \mathrm{W}$ with obvious left-lateral motion (Figs. 3a, e, f, and g). At the running tracks, the northernmost N-S striking fracture is subparallel to other fractures with sinistral motion while the rest fractures with the strike of $\sim \mathrm{N} 23^{\circ} \mathrm{W}$ demonstrate tension fea- tures with some minor dextral movement (Figs. $3 b$ and d). The first fracture can be interpreted as synthetic Riedel shear $(\mathrm{R})$ and the latter are tension fractures $(\mathrm{T})$, consistent with principal displacement zone (PDZ) in the direction of $\sim \mathrm{N} 20^{\circ} \mathrm{E}$. The other branch broke the surface at the front gate of the campus and the brick pavement in front of the stadium (Fig. 3c). Fractures in front of the stadium are shorter and more compressional compared to those on the running tracks. The fractures here are dominated by pushup features as deformation is constrained by the shape and strength of the bricks. South of the stadium, the two fracture zones seem to join together and run across Jiaxin Road.

\subsection{Northern Meilun Mountain}

South of the IRP campus around northern Meilun Mountain, mapped surface breakages are in general parallel

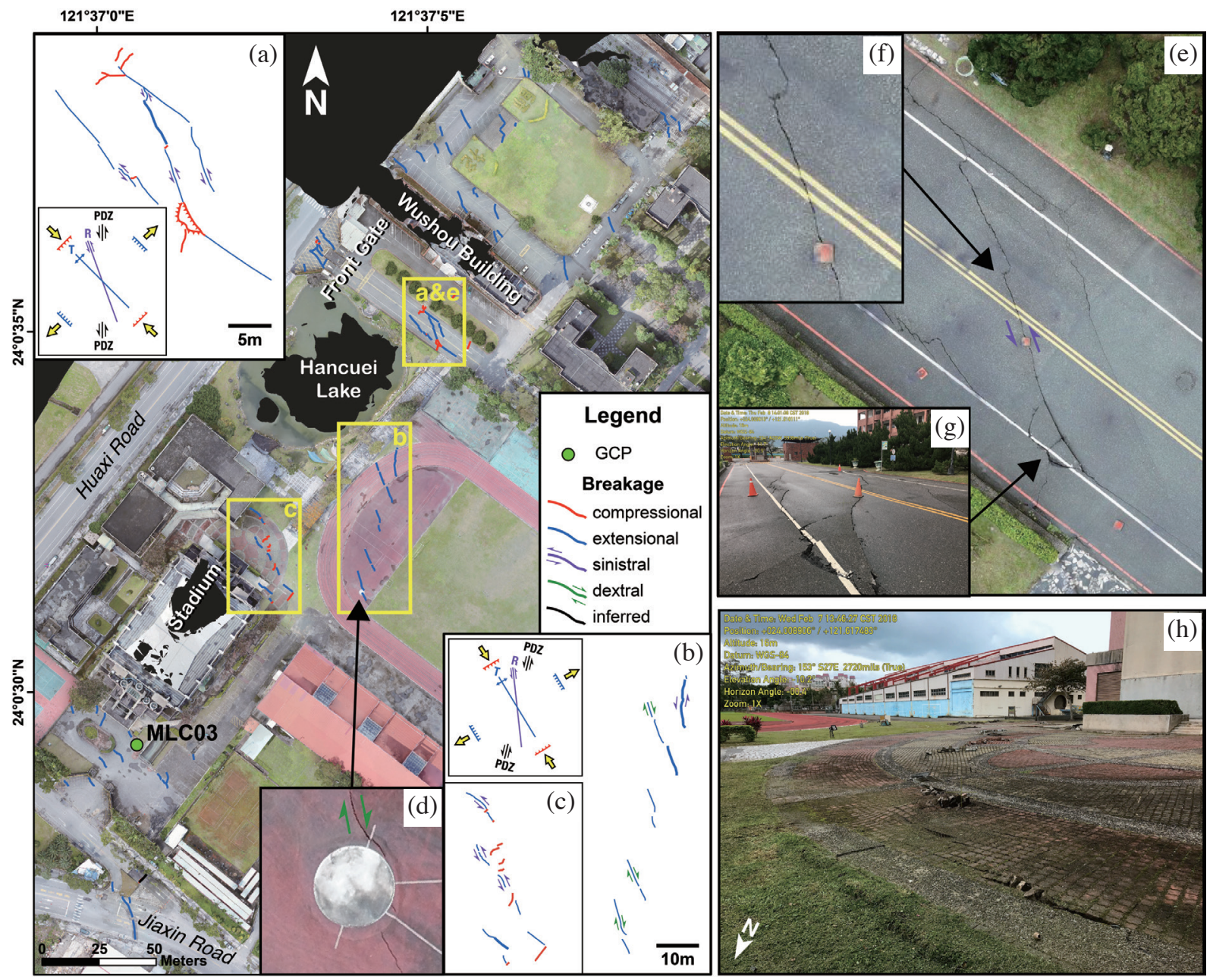

Fig. 3. Mapping of surface breakages in IRP, National Dong Hwa University. (a) Detailed mapping of surface fractures south of Wushou Building. Inset shows the conceptual setting of the stress field and structure orientations. (b) Detailed mapping of surface fractures on the running tracks. Inset shows the conceptual setting of the stress field and structure orientations. (c) Detailed mapping of surface fractures in front of the stadium. (d) Aerial image of fractures across the running tracks showing right lateral movement. (e) Aerial image of surface fractures south of Wushou Building. (f) Enlarged aerial image showing left-lateral movement across the solid double yellow line. (g) Field photo of (e). (h) Field photo of (c) showing compressed bricks. 
to Shangzhi Road with the strike of $\mathrm{N} 20^{\circ} \mathrm{E}$. South of Jiaxin Road, the fault trace is within orchards and groves so we only identified few fractures (Fig. 4). On XinXing Road around the northern tip of Meilun Mountain, the rupture transects the road with sinistral movement and push-up mole tracks (Fig. 4a). In addition to orthoimages, the SfM-MVS method generates 3D models and DSMs, showing topography and surface relief. According to the 3D model (Fig. 5a), the white side line to the south is offset sinistrally and the fractures across the road shows stepovers with features of angular ridges. DSM produced by the SfM-MVS method is also helpful for identify such features (Fig. 5b). A topographic profile estimates the height of $25 \mathrm{~cm}$ for the largest angular ridge (Fig. 5c). To the south note that the rupture climbed up to foothills instead of ran along the western boundary of Meilun Mountain. The strike of surface breakages become $\mathrm{N}-\mathrm{S}$ striking tension fissures as going uphill to a banana orchard (Figs. 4b and c). Toward south, surface ruptures seem transect the Shangzhi Water Purification Plaint, causing pipeline leakage and water outage for several days after the earthquake.

\subsection{Western Meilun Mountain}

To the western edge of Meilun Mountain, surface breakages are present along the western side of Shangzhi Road. The surface fractures around northern Meilun Mountain seem to be vanished south of the Shangzhi Water Purification Plaint in the hills, and at the same latitude to the west the surface fractures start to be present along the western edge of Meilun Mountain, suggesting a major stepover of surface ruptures. At the western tip of Meilun Mountain where Shangzhi Road alongside Meilun River, compression fractures mainly followed the western side of Shangzhi Road and crossed a tour bus parking lot (Fig. 6a). The orientations and types of surface breakages at the bus parking lot may result from its foundation strength instead of the fault movement. Since the rupture is within the foothills of northern Meilun Mountain (Fig. 4) and is along the edge of the mountain here, it seems that the fault trace steps down from the foothills to the foot of Meilun Mountain. In addition, because multiple fractures broke the both sides of Meilun River embankments (Fig. 6) and few surface breakages are found along the eastern side of the river south of this point (Fig. 7), it is plausible that the fault trace crossed the river around the western tip of Meilun Mountain.

\subsection{East of Downtown Hualien}

South of Meilun Mountain, surface fractures are extensively distributed across eastern downtown Hualien. Near the Martyr's shrine, fractures were present at both sides of Shangzhi Bridge (Fig. 7). The preliminary field investigations documented severe damages at the western side of
Shangzhi Bridge (CGS 2018); however, we failed to collect images at the place. Therefore, the fault trace could connect from the western edge of Meilun Mountain to the western side of Shangzhi Bridge. Further south, surface fractures seem to be restrained in between streets and open fields. Tensional shears were mapped mainly in the direction of $\mathrm{N} 35^{\circ} \mathrm{W}$ and compression fractures generally follow the direction of $\mathrm{N} 55^{\circ} \mathrm{E}$ (Fig. 7). Fractures at open fields like tarred fields west of the collapsed Marshal Hotel have a little bit more diverse and oblique orientations. Note that it is somewhat difficult to map surface fractures within such urban areas on the orthoimages, especially when fractures are present along the edges of buildings or under the verandas. Overalls, surface fractures in eastern downtown Hualien display distributed patterns with restraints from surrounding buildings. Compared to the surface rupture lines of the October 1951 earthquake (CGS 2018), surface fractures of the 2018 Hualien earthquake in downtown Hualien City are more distributed (Fig. 7).

\subsection{Southern Hualien City}

Towards southern Hualien City where the surface trace of the Milun fault ends (Fig. 1), surface breakages are concentrated along the western part of the Dondamen Nightmarket and distributed extensively across the whole Nanbin Park. At a tarred field right north of the nightmarket, a series of $\mathrm{N} 30-40^{\circ} \mathrm{W}$ striking sinistral fissures connected by $\mathrm{N} 50^{\circ} \mathrm{E}$ striking push-up mole tracks, implying an almost N-S striking PDZ (Figs. 8a and c). South of the tarred field, fractures are located at the western part of the nightmarket and along Ziyou Road. To the southwest of the nightmarket, surface breakages show similar patterns to those at the tarred field with the PDZ strike of $\sim \mathrm{N} 15^{\circ} \mathrm{W}$ (Fig. 8b). Further south, extensive tensional fissures are distributed along Nanbin Road and across Nanbin Park (Fig. 8). The northernmost fissure $\left(\sim \mathrm{N} 25^{\circ} \mathrm{W}\right)$ along the bicycle route at the eastern side of Nanbin Park is the largest one with extension of several tens of centimeters. This fissure seems to align with the fracture sets in Figs. 8a and b, denoting a likely curved trace of the PDZ.

\subsection{Hualien Bridge}

In Hualien River, the surface ruptures offset Hualien Bridge and broke the surface of the western floodplain, suggesting that the northern segment of the Longitudinal Valley fault (Shyu et al. 2016) or Linding fault (CGS 2012) is active during the earthquake. According to our orthoimages and 3D model, the forth bridge segment from the east is offset in a sense of left-lateral strike-slip motion, indicating the fault trace ran below this bridge segment (Fig. 9a). In addition, we measured the amount of sinistral offset by using a Leica TCRA 1201+ R1000 Total Station. We measured along the 

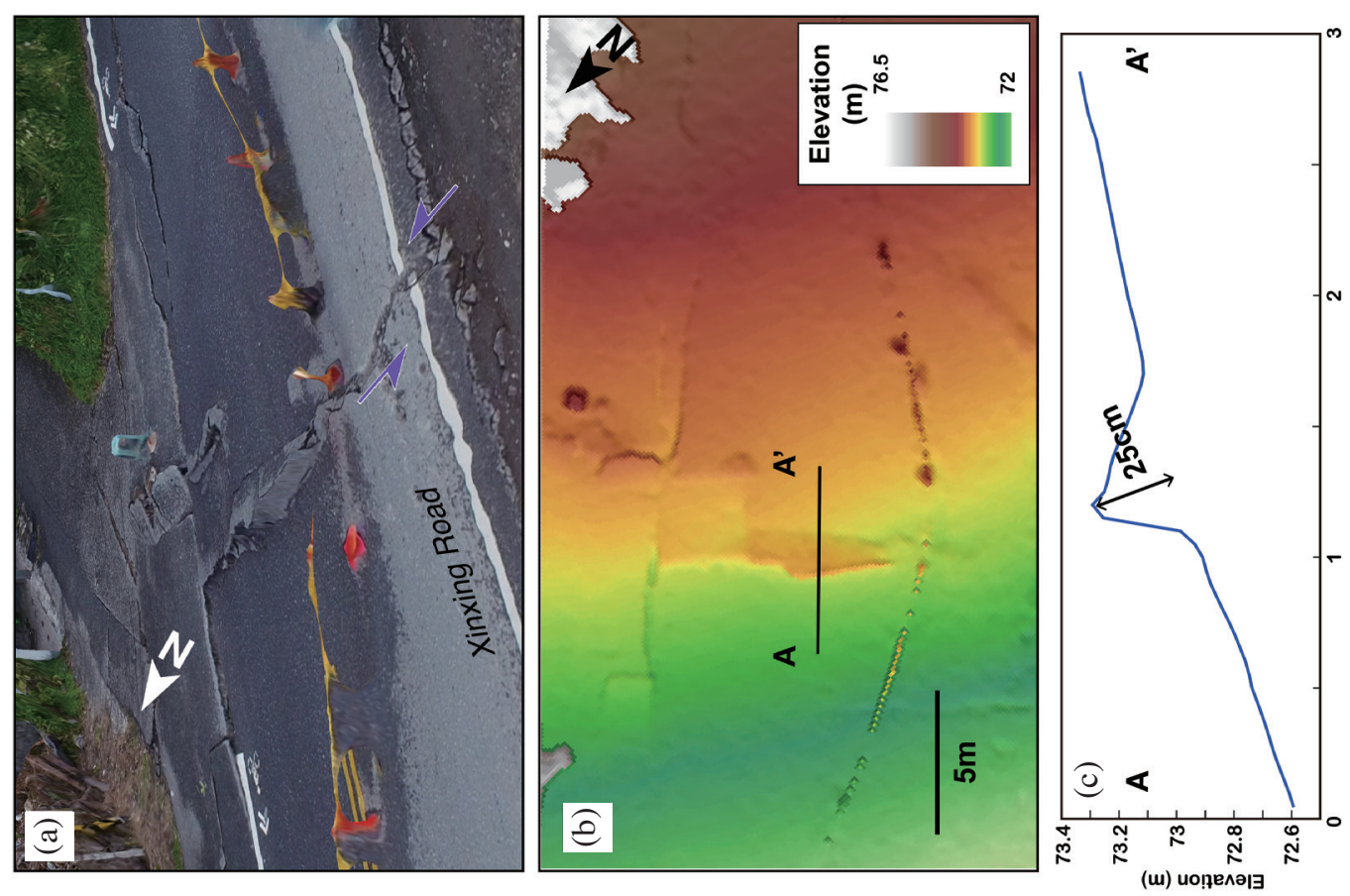

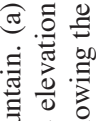

용 क

$\Xi$ चं 。

$\sum^{\infty} \simeq$

톨

층

$\Xi$ 이

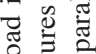

늘

政

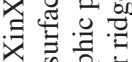

ธ

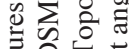

월웡

षे

응

峵贾

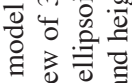

굥

믈⿺

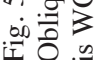

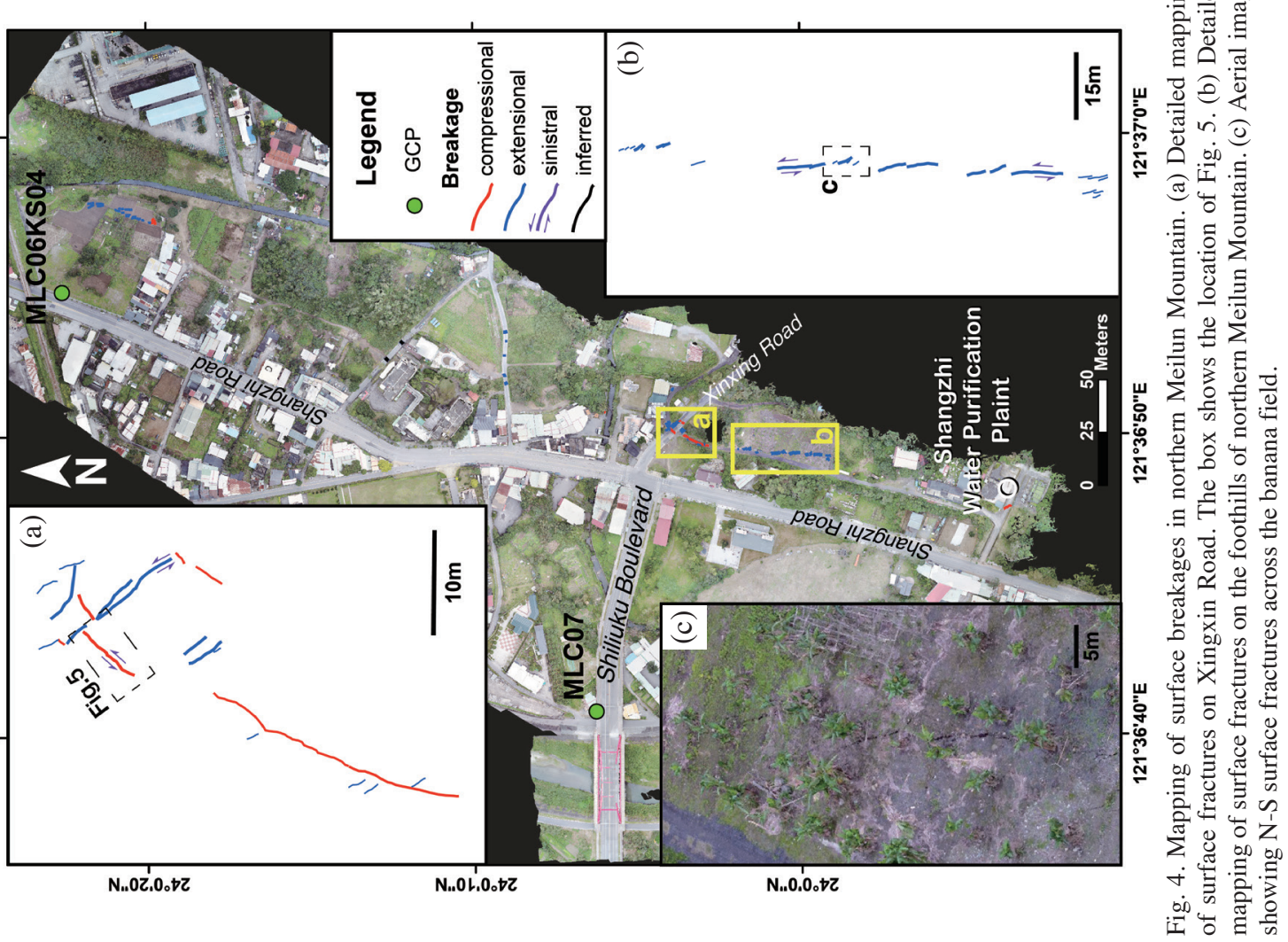




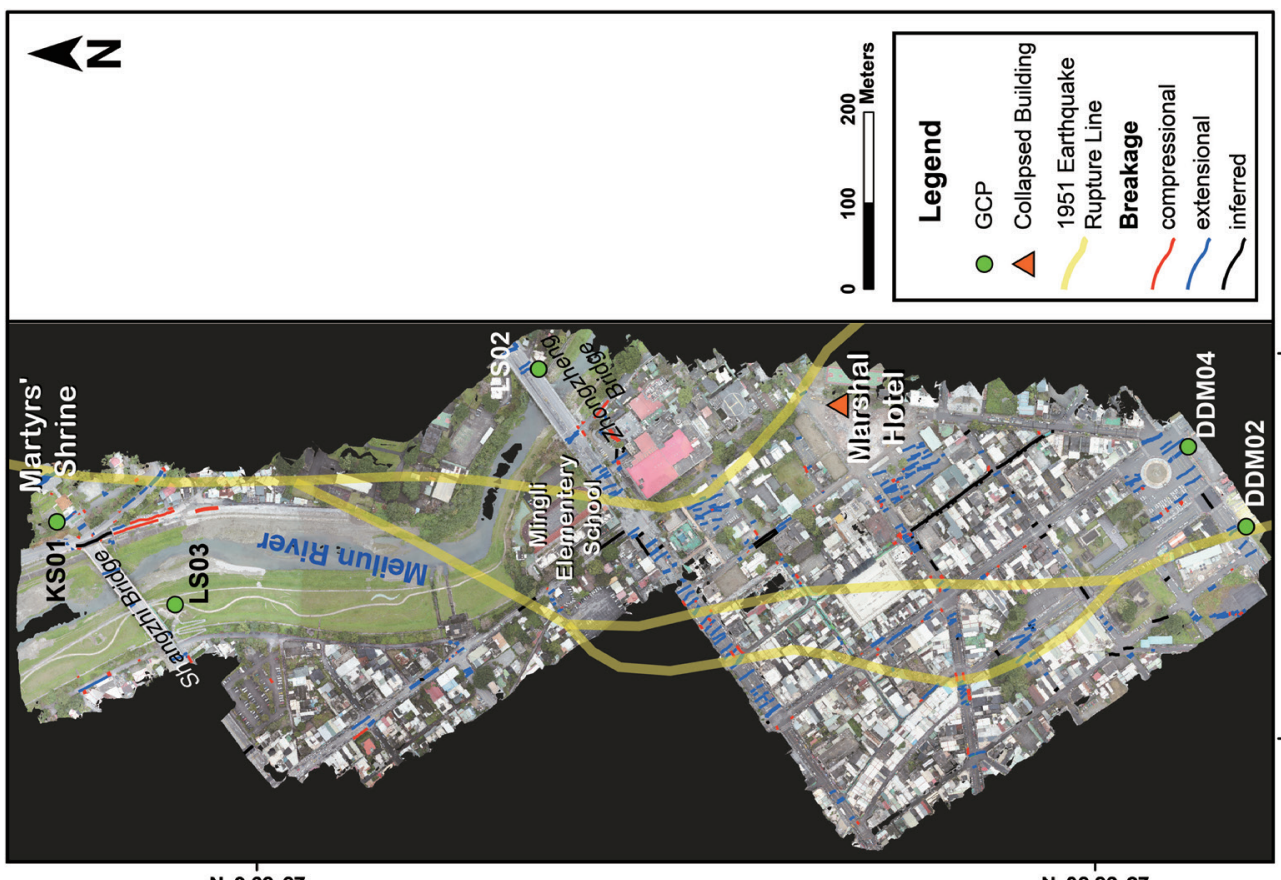

N..0.6S。\&Z

N..0\&.8G.\&Z

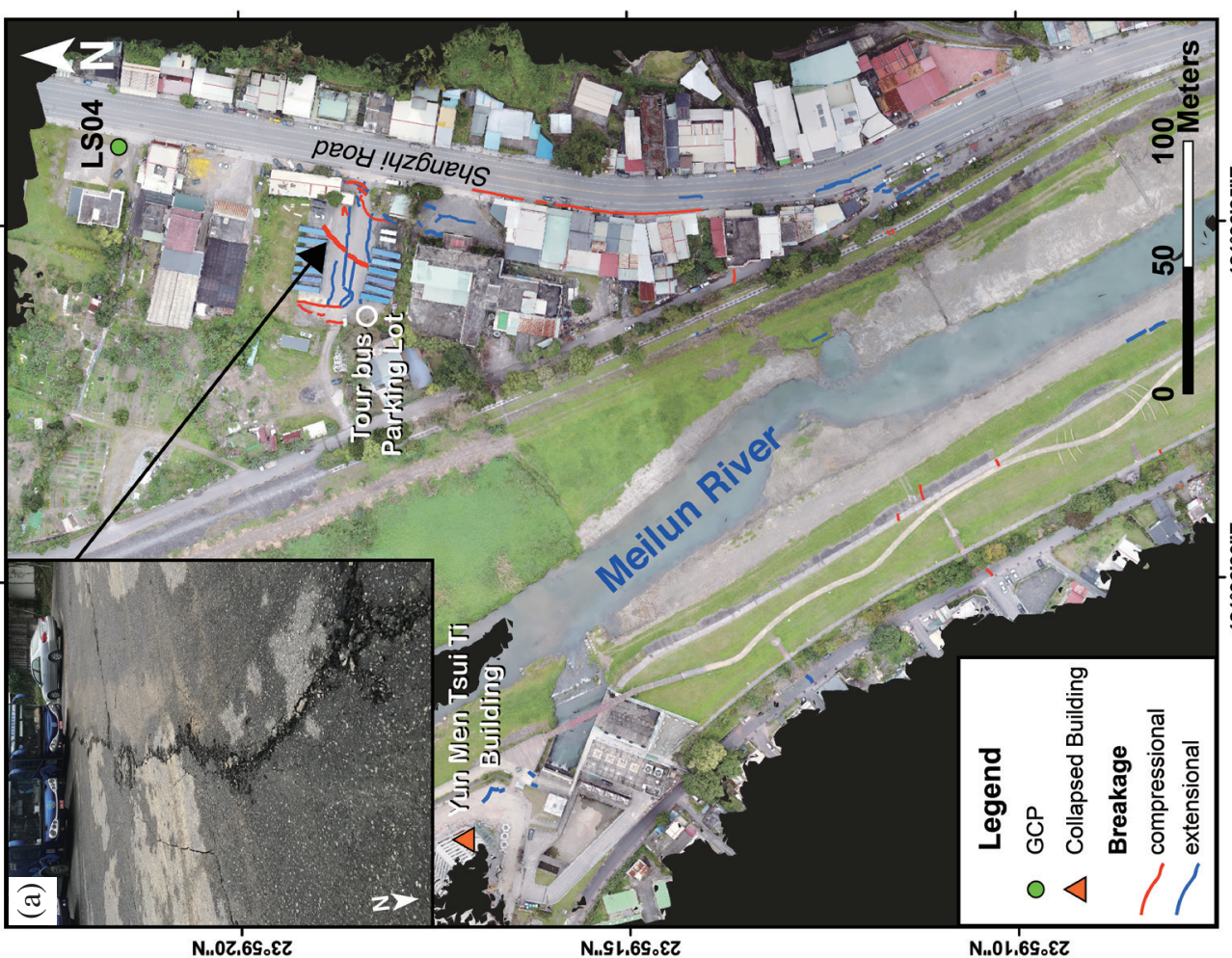

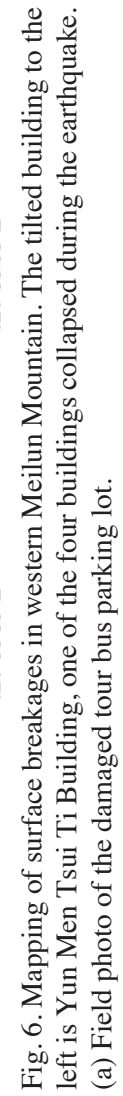



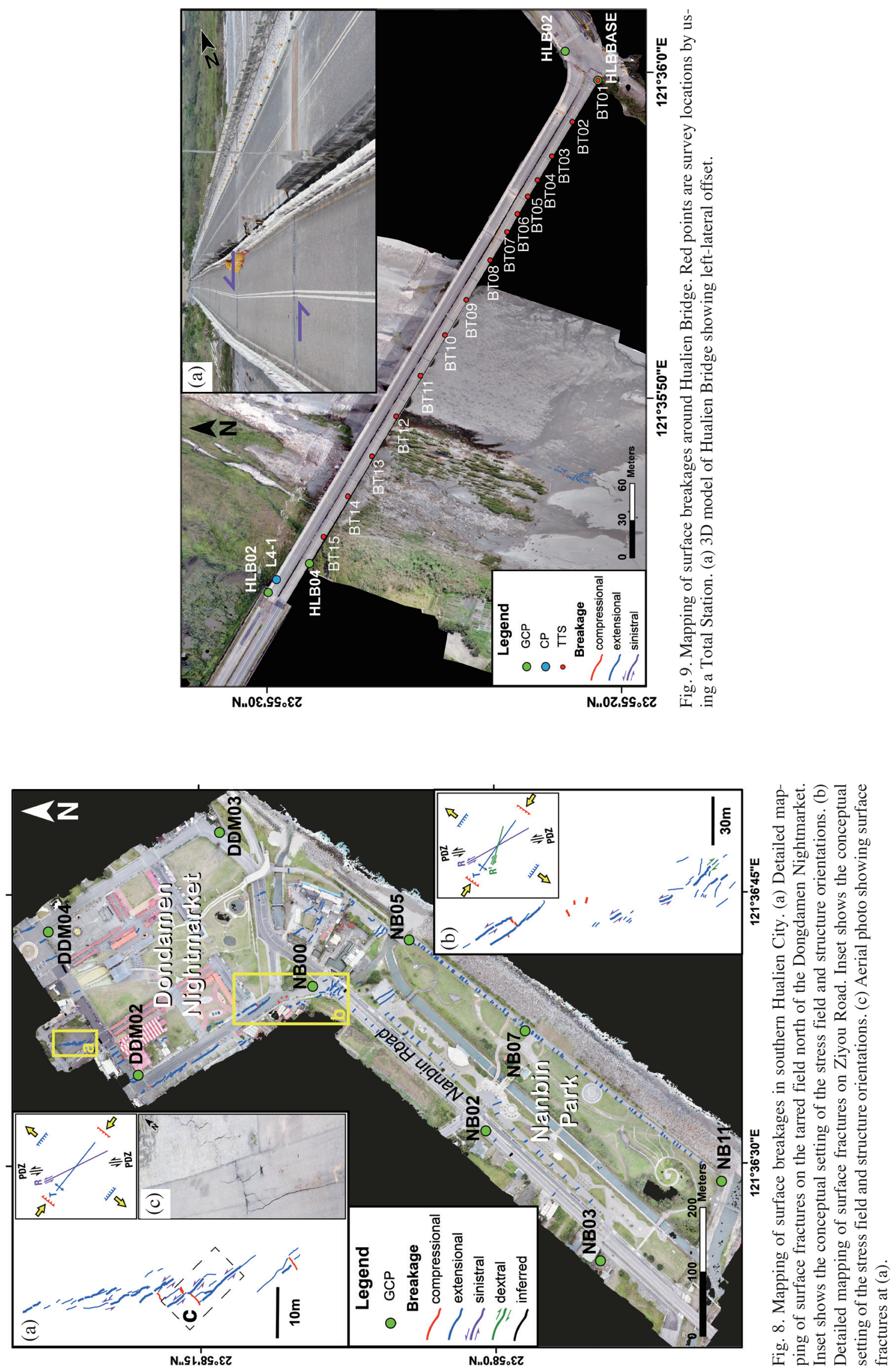
western side line and estimated $~ 70-\mathrm{cm}$ offset (Fig. 10). In the western floodplain south of the bridge, dense surface breakages are present in a short distance of $40 \mathrm{~m}$ (Fig. 9). This set of breakages seem to be parallel to the Linding fault but out of alignment with the offset bridge segment. Thus, the breakages in the floodplain may not represent the location of the surface trace of the Linding fault.

\section{DISCUSSION}

\subsection{Characteristics of Surface Ruptures}

Mapped surface breakages for the 2018 Hualien earthquake based on UAS photogrammetry, which provides georeferenced orthoimages for surface mapping, demonstrate varied deformation styles along the Milun and Linding faults, suggesting coseismic movement along these two faults. The UAS surveys were initially planned to be along the Milun fault (Fig. 1a) and further extended to the area of Hualien Bridge where the Linding fault passes (Fig. 1b). The mapping results show that surface fractures were present in all areas surveyed, suggesting active motion during the Hualien earthquake for the entire Milun fault and northern Linding fault at Hualien Bridge. Most surface fractures documented in the preliminary field reports (CGS 2018; ETEC 2018) were mapped in our orthoimages with accurate surface geometry and coordinates, helpful for us to examine structural characteristics of surface fractures.

According to our mapping results, surface breakages show complex and varied fractures, usually in en échelon arrays. Instead of a through-going fault, the surface ruptures of the Hualien earthquake display many sets of tensional shears, sometimes connected by push-up mole tracks, at different localities. The tensional shears could be sinistral or dextral and their orientations are generally oblique to the strike of PDZ, suggesting that these shears are associated structures such as Riedel shear (R) or antithetic Riedel shear $\left(R^{\prime}\right)$ rather than main fault trace itself. Some tensional shears may be tension fractures (T) (e.g., Fig. 3b) according to the standard geometric patterns of structures in strike-slip models (e.g., Sylvester 1988). Compression structures like pushup mole tracks with angular ridges or bulge patterns usually perpendicularly interconnect sinistral structures (e.g., Figs. 8a and b). If the sinistral structures are Riedel shears, the compression structures could be secondary antithetic Riedel shear based on their relative orientations.

The variations of orientations and slip senses between mapped fractures and ideal associated structures may result from fault geometry, oblique slip, and strength of surface materials (e.g., Dooley and Schreurs 2012). The Milun fault is a high-angle east-dipping fault (Shyu et al. 2016) rather than a pure strike-slip vertical fault. The Milun fault produced both vertical and left-lateral movements during the October 1951 event (Hsu 1954; Bonilla 1975, 1977) and generated at least some vertical motion in the north during the 2018 earthquake (CGS 2018; ETEC 2018). In addition, to the south in the areas of downtown Hualien City, shear structures occurred mainly parallel and perpendicular to roads in between buildings but arranged in more oblique orientations at more open fields (Fig. 7), implying the strength of surface and surrounding materials could predominantly affect the orientations of surface fractures. Moreover, strike-slip fault in unconsolidated deposits could display varied structures (e.g., Rao et al. 2011) as the surface areas along the Milun fault are composed of fluvial deposits.

\subsection{Along-Strike Variations of Surface Deformation}

Surface ruptures of the Hualien earthquake show orientation changes from the north to south, basically along the trace of the Milun fault. As mentioned above, surface ruptures along the fault generally display en échelon arrays of tensional shears connected by push-up mole tracks without discrete through-going fault, but we are able to estimate the strike of PDZ based on bulk orientation of the en échelon arrays. At the northernmost surface ruptures along the Milun fault in Chihsingtan, the strike of PDZ is about $N 65^{\circ} \mathrm{E}$ and it changes counterclockwise as going south (Fig. 11a). The strike of major PDZ become $\sim \mathrm{N} 25^{\circ} \mathrm{W}$ at the southernmost ruptures in Nanbin Park. The locations and strikes of the surface PDZs in general follow the western edge of the Meilun Tableland and the trace of the Milun fault, proving that the Milun fault indeed ruptured during the 2018 Hualien earthquake. Based on our mapping results, the Linding fault also ruptured during the earthquake although we did not find any other obvious ruptures of the fault. This is likely because the Linding fault is located within the course of Hualien River and covered by river water, which makes difficult to estimate the rupture length of the Linding fault.

In addition to the orientation changes of the fault trace, amount of slip varies along the strike of the fault. Since we mainly mapped surface fractures based on orthoimages, we estimate along-strike sinistral offsets of single and accumulative fractures (e.g., Angelier et al. 2004) (Fig. 11b). The ruptures in the north show significant sinistral offsets of more than $60 \mathrm{~cm}$ and the amount of sinistral slip decreases toward south. It is difficult to estimate slip amount around the areas near Meilun Mountain where surface fractures display compression features or even slightly dextral movements. The ruptures around eastern downtown Hualien is extensively distributed (Fig. 7) so the estimated slip here may be underestimated. In addition, we estimate left-lateral fault slip based on surface displacements derived from InSAR (Yen et al. 2018) for comparison. We compute the differences of the horizontal displacements parallel to the direction of fault strikes across the Milun fault. The comparison indicates that the estimated sinistral fault movements derived from our UAS photogrammetry and InSAR are consistent (Fig. 11b), showing the tendency of large offset to the north and smaller 

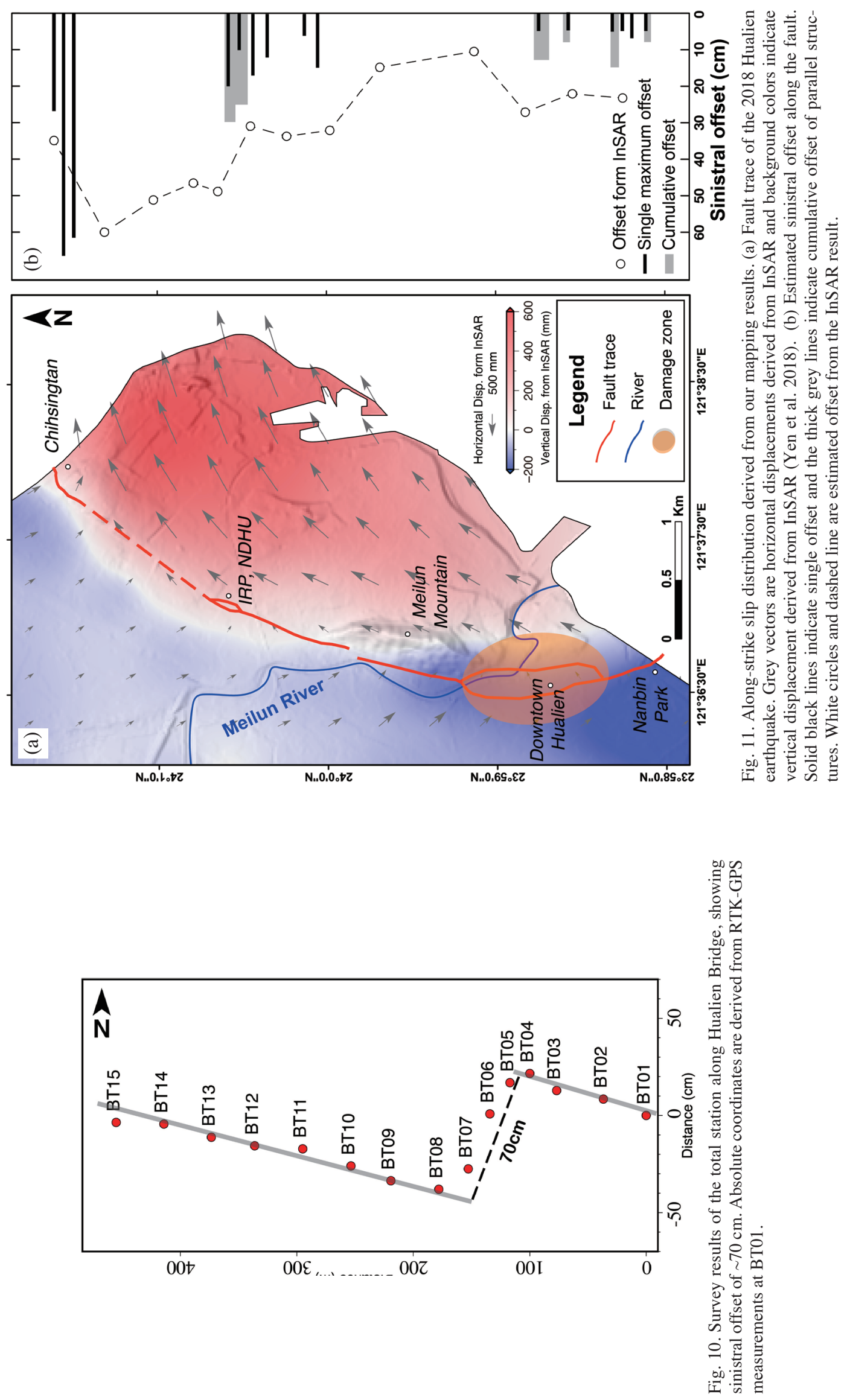
offset to the south. For the vertical offset, we only observe obvious uplift along Lane 53 of Chihsing Street. Other compressional features seem to be more like push-up mole tracks (e.g., Fig. 5). The observed uplift feature in Chihsingtan is consistent with preliminary field investigations (CGS 2018; ETEC 2018). Unfortunately, the feature is right in front of local buildings so the 3D model produced by the SfM-MVS method is distorted, making us difficult to estimate vertical offsets directly from the 3D model.

Fault behaviors of the 2018 Hualien earthquake is somewhat different from the October 1951 event. As reported in previous studies (Hsu 1962; Bonilla 1975, 1977), the Milun fault exhibits both horizontal and vertical displacements more than a meter, which is never seen in the 2018 earthquake. The surface ruptures of the 2018 earthquake show both large sinistral and vertical displacements mainly in Chihsingtan. The faulting style of the 2018 event is varied along the strike as well. At IRP campus, the fault bifurcates into two branches locally. In downtown Hualien, surface ruptures are distributed, forming a large damage zone (Fig. 11a). The localities of major PDZs in the southern part seems not fit the surface ruptures of the 1951 event (Fig. 7). Therefore, although the entire Milun fault indeed ruptured during the 2018 earthquake, the fault slip could be different and smaller compared to the 1951 event.

\subsection{Efficiency of Surface Mapping by UAS Photogrammetry}

UAS surveys and photogrammetry of the 2018 Hualien earthquake demonstrate great potential for detailed mapping of surface ruptures. In the cases of coseismic investigations, the first priority is imagery collection, which is well served by drones. The challenge of geologic investigations for earthquake damages is to document the localities, damage styles, and deformation amounts of surface ruptures along the fault in order to estimate coseismic slip distributions and magnitude as rescue missions and transportation recovery may eliminate surface fractures, especially in urban areas. The advantages of overlooking and mobility for drones give rapid, extensive aerial surveys, which are not interfering and interfered by the rescue and recovery missions. In addition, orthomosaic images processed by the SfM-MVS software are georeferenced. The georeferenced images provide a basis for mapping digitally the surface geometry and the attitudes of coseismic fractures. More specifically, surface mapping by using the orthoimages can well digitize the shape of each fracture while field investigations generally record surface damages in non-georeferenced photos and sketches.

In order to obtain useful aerial images, it requires careful plans for drone surveys of seismic damages. The experience of UAS surveys for the 2018 Hualien earthquake gives us insights into future missions. The first challenge is to decide the areas of aerial surveys. It could take some time for geologists to figure out which fault ruptured and where surface ruptures are. Communication between field geologists and drone crews is significantly important to determine aerial survey areas. On the other hand, aerial images can help to guide field geologists where to check surface ruptures. Drone crews also need to update information of rescue missions and transportation recovery from the governments. Areas subject to early recovery may need image collection in priority. Second, drone crews should pay attention to weather conditions and flight authorizations. Currently, low-cost drones are not suitable in windy or rainy conditions, which could limit the progress of UAS surveys. Flight authorizations can spatially limit survey areas. In our study, the area between Chihsingtan and IRP, National Dong Hwa University is not surveyed by UAS because surface damages are within the Hualien airport and build-in security functions of the UAS prohibit drone actions in such areas.

The SfM-MVS method can play an important role for seismic damage investigations in the future. The drone surveys for the Hualien earthquake took about 3 days to finish flight missions. For larger areas, it could take more time to collect images with the same resolution. In such cases, greater flight heights and different drones (e.g., fixed-wing UAVs) or payloads (e.g., LiDAR) are options. In order to generate orthoimages, nonetheless, the process of the SfMMVS software for extensive areas is in fact computationally expensive and time consuming, which significant influence the progress of surface mapping. The improvement of computer hardware can always shorten this process in the future. If ruptures are too close to buildings, for example in Chihsingtan or downtown Hualien, 3D models could be distorted. This may be problematic for estimating vertical offsets of reverse faults. More oblique images can help to resolve this problem. Moreover, the SfM-MVS can process not only aerial images but also multi-view images taken by regular cameras, which may be helpful to construct better 3D models at independent localities. Such 3D models constructed by the SfM-MVS methods can also help us to understand the characteristics of geologic structures (e.g., Thiele et al. 2015).

\section{CONCLUSION}

We use UAS photogrammetry to map surface breakages associated with the 2018 Hualien, Taiwan, earthquake. The $\mathrm{M}_{\mathrm{w}}$ 6.4 Hualien earthquake generated extensive surface breakages over a distance of $\sim 8 \mathrm{~km}$ along the Milun fault, which ruptured during the October 1951 Hualien earthquake. The low-cost UAS helped us to conduct wideranging surveys and imagery collection. The SfM-MVS photogrammetric technique together with control surveys of GCPs produced high-resolution orthoimages for us to map the surface breakages. The mapped surface fractures are often in en échelon arrays or distributed fractures. We 
estimate orientations of PDZs and sinistral movement base on the orthoimages and confirm that surface ruptures follow the trace of the Milun fault and northern Linding fault, suggesting that both faults indeed were active during the earthquake. The estimated sinistral offset is more than $60 \mathrm{~cm}$ in Chihsingtan and decreases toward south. The ruptures bifurcated into two branches at the IRP campus and demonstrate a major stepover in western Meilun Mountain. The fractures in downtown Hualien seem to be distributed differently than the surface ruptures of the October 1951 earthquake. Thus, the fault behavior of the 2018 Hualien earthquake shows along-strike variations and is somewhat different from the October 1951 earthquake.

Acknowledgements We thank the National Science and Technology Center for Disaster Reduction (NCDR) for the assistance for applying flight permission. We thank the Central Weather Burau (CWB), Central Geological Survey (CGS) and Eastern Taiwan Earthquake Research Center (ETEC) for providing information of the earthquake and surface damages. We thank the Sinotech Engineering Consultants Inc. for sharing results of surface investigations. We thank Ling-Ho Chung, Po-Tsun Lee, Yu Wang, and Wen-Jeng Huang for helpful suggestions and discussion. We thank Chao-Jung Chiang, Yi-Chieh Lee, Wan-Tzu Liu, Hsiang-Chieh Liu, Chuan-Min Chao, and Chi-Wei Lin for the assistance of field work. This work was supported by the MOST project 106-2116-M-002-007- and the Research Center for Future Earth, National Taiwan University.

\section{REFERENCES}

Adams, S. M. and C. J. Friedland, 2011: A survey of unmanned aerial vehicle (UAV) usage for imagery collection in disaster research and management. 9th International Workshop on Remote Sensing for Disaster Response, Vol. 8.

Angelier, J., F. Bergerat, M. Bellou, and C. Homberg, 2004: Co-seismic strike-slip fault displacement determined from push-up structures: The Selsund Fault case, south Iceland. J. Struct. Geol., 26, 709-724, doi: 10.1016/j. jsg.2003.07.006. [Link]

Baiocchi, V., D. Dominici, and M. Mormile, 2013: UAV application in post - seismic environment. Int. Arch. Photogramm. Remote Sens. Spatial Inf. Sci., XL-1/W2, 21-25, doi: 10.5194/isprsarchives-xl-1-w2-21-2013. [Link]

Bemis, S. P., S. Micklethwaite, D. Turner, M. R. James, S. Akciz, S. T. Thiele, and H. A. Bangash, 2014: Groundbased and UAV-based photogrammetry: A multi-scale, high-resolution mapping tool for structural geology and paleoseismology. J. Struct. Geol., 69, 163-178, doi: 10.1016/j.jsg.2014.10.007. [Link]

Bi, H., W. Zheng, Z. Ren, J. Zeng, and J. Yu, 2017: Using an unmanned aerial vehicle for topography mapping of the fault zone based on structure from motion photogrammetry. Int. J. Remote Sens., 38, 2495-2510, doi: 10.1080/01431161.2016.1249308. [Link]

Bonilla, M. G., 1975: A review of recently active faults in Taiwan. U.S. Geological Survey Open-File Report 7541, Version 1.1, Reston, VA, 42 pp. Available at http:// geopubs.wr.usgs.gov/open-file/of75-41/.

Bonilla, M. G., 1977: Summary of Quaternary faulting and elevation changes in Taiwan. Mem. Geol. Soc. China, 2, 43-55.

Carrivick, J. L., M. W. Smith, D. J. Quincey, and S. J. Carver, 2013: Developments in budget remote sensing for the geosciences. Geology Today, 29, 138-143, doi: 10.1111/gto.12015. [Link]

CGS, 2012: Active Fault Map of Taiwan, Central Geological Survey, Taipei. Available at https://twgeoref.moeacgs.gov.tw/GipOpenWeb/wSite/public/ Attachment/2014/20143535/102-a3-CH.jpg.

CGS, 2018: Geological Report of 2018 Hualien Earthquake, Central Geological Survey report, Taipei, 131 pp. (in Chinese)

Chen, C. Y., J. C. Lee, Y. G. Chen, and R. F. Chen, 2014: Campaigned GPS on present-day crustal deformation in northernmost Longitudinal Valley preliminary results, Hualien Taiwan. Terr. Atmos. Ocean. Sci., 25, 337-357, doi: 10.3319/TAO.2013.12.25.01(TT). [Link]

Clapuyt, F., V. Vanacker, and K. Van Oost, 2016: Reproducibility of UAV-based earth topography reconstructions based on Structure-from-Motion algorithms. Geomorphology, 260, 4-15, doi: 10.1016/j.geomorph.2015.05.011. [Link]

Colomina, I. and P. Molina, 2014: Unmanned aerial systems for photogrammetry and remote sensing: A review. ISPRS J. Photogram. Rem. Sens., 92, 79-97, doi: 10.1016/j.isprsjprs.2014.02.013. [Link]

Cook, K. L., 2017: An evaluation of the effectiveness of low-cost UAVs and structure from motion for geomorphic change detection. Geomorphology, 278, 195-208, doi: 10.1016/j.geomorph.2016.11.009. [Link]

Deffontaines, B., K. J. Chang, J. Champenois, K. C. Lin, C. T. Lee, R. F. Chen, J. C. Hu, and S. Magalhaes, 2018: Active tectonics of the onshore Hengchun Fault using UAS DSM combined with ALOS PS-InSAR time series (Southern Taiwan). Nat. Hazards Earth Syst. Sci., 18, 829-845, doi: 10.5194/nhess-18-829-2018. [Link]

d'Oleire-Oltmanns, S., I. Marzolff, K. D. Peter, and J. B. Ries, 2012: Unmanned aerial vehicle (UAV) for monitoring soil erosion in Morocco. Remote Sens., 4, 33903416, doi: 10.3390/rs4113390. [Link]

Dominici, D., M. Alicandro, and V. Massimi, 2017: UAV photogrammetry in the post-earthquake scenario: Case studies in L'Aquila. Geomatics, Natural Hazards and 
Risk, 8, 87-103, doi: 10.1080/19475705.2016.1176605. [Link]

Dooley, T. P. and G. Schreurs, 2012: Analogue modelling of intraplate strike-slip tectonics: A review and new experimental results. Tectonophysics, 574-575, 1-71, doi: 10.1016/j.tecto.2012.05.030. [Link]

ETEC, 2018: Preliminary report on 20180206 Hualien earthquake. Technical report, Eastern Taiwan Earthquake Research Center, National Dong Hua University, Hualien, 42 pp. (in Chinese)

Favalli, M., A. Fornaciai, I. Isola, S. Tarquini, and L. Nannipieri, 2012: Multiview 3D reconstruction in geosciences. Comput. Geosci., 44, 168-176, doi: 10.1016/j. cageo.2011.09.012. [Link]

Fonstad, M. A., J. T. Dietrich, B. C. Courville, J. L. Jensen, and P. E. Carbonneau, 2013: Topographic structure from motion: A new development in photogrammetric measurement. Earth Surf. Process. Landf., 38, 421430, doi: 10.1002/esp.3366. [Link]

Gao, M., X. Xu, Y. Klinger, J. van der Woerd, and P. Tapponnier, 2017: High-resolution mapping based on an Unmanned Aerial Vehicle (UAV) to capture paleoseismic offsets along the Altyn-Tagh fault, China. Sci. Rep., 7, doi: 10.1038/s41598-017-08119-2. [Link]

Gomez, C. and H. Purdie, 2016: UAV- based photograpmmetry and geocomputing for hazards and disaster risk monitoring - A review. Geoenvironmental Disasters, 3, doi: 10.1186/s40677-016-0060-y. [Link]

Harwin, S. and A. Lucieer, 2012: Assessing the accuracy of georeferenced point clouds produced via multiview stereopsis from unmanned aerial vehicle (UAV) imagery. Remote Sens., 4, 1573-1599, doi: 10.3390/ rs4061573. [Link]

Hsu, T. L., 1954: On the geomorphic features and the recent uplifting movement of the Coastal Range, eastern Taiwan. Bull. Geol. Surv. Taiwan, 7, 9-18. (in Chinese)

Hsu, T. L., 1962: Recent faulting in the Longitudinal Valley of eastern Taiwan. Mem. Geol. Soc. China, 1, 95-102.

Hugenholtz, C. H., B. J. Moorman, K. Riddell, and K. Whitehead, 2012: Small unmanned aircraft systems for remote sensing and Earth science research. Eos, Trans., $A G U$, 93, 236-236, doi: 10.1029/2012EO250005. [Link]

Hugenholtz, C. H., K. Whitehead, O. W. Brown, T. E. Barchyn, B. J. Moorman, A. LeClair, K. Riddell, and T. Hamilton, 2013: Geomorphological mapping with a small unmanned aircraft system (sUAS): Feature detection and accuracy assessment of a photogrammetrically-derived digital terrain model. Geomorphology, 194, 16-24, doi: 10.1016/j.geomorph.2013.03.023. [Link]

James, M. R. and S. Robson, 2012: Straightforward reconstruction of 3D surfaces and topography with a camera: Accuracy and geoscience application.J.Geophys.Res., 117, F03017, doi: 10.1029/2011JF002289. [Link]
James, M. R., S. Robson, S. d'Oleire-Oltmanns, and U. Niethammer, 2017: Optimising UAV topographic surveys processed with structure-from-motion: Ground control quality, quantity and bundle adjustment. Geomorphology, 280,51-66, doi: 10.1016/j.geomorph.2016.11.021. [Link]

Johnson, K., E. Nissen, S. Saripalli, J. R. Arrowsmith, P. McGarey, K. Scharer, P. Williams, and K. Blisniuk, 2014: Rapid mapping of ultrafine fault zone topography with structure from motion. Geosphere, 10, 969986, doi: 10.1130/GES01017.1. [Link]

Klemas, V. V., 2015: Coastal and environmental remote sensing from unmanned aerial vehicles: An overview. J. Coast. Res., 31, 1260-1267, doi: 10.2112/JCOASTRES-D-15-00005.1. [Link]

Konagai, K., T. Kiyota, M. Shiga, H. Tomita, H. Okuda, and K. Kajihara, 2016: Ground fissures that appeared in Aso Caldera Basin in the 2016 Kumamoto Earthquake, Japan. JSCE Journal of Disaster FactSheets, FS2016-E-0003.

Langhammer, J. and T. Vacková, 2018: Detection and mapping of the geomorphic effects of flooding using UAV photogrammetry. Pure Appl. Geophys., 175, 32233245, doi: 10.1007/s00024-018-1874-1. [Link]

Lazarte, C. A., J. D. Bray, A. M. Johnson, and R. E. Lemmer, 1994: Surface breakage of the 1992 Landers earthquake and its effects on structures. Bull. Seismol. Soc. Am., 84, 547-561.

Lucieer, A., S. M. de Jong, and D. Turner, 2014: Mapping landslide displacements using Structure from Motion (SfM) and image correlation of multi-temporal UAV photography. Prog. Phys. Geogr., 38, 97-116, doi: 10.1177/0309133313515293. [Link]

Mancini, F., M. Dubbini, M. Gattelli, F. Stecchi, S. Fabbri, and G. Gabbianelli, 2013: Using unmanned aerial vehicles (UAV) for high-resolution reconstruction of topography: The structure from motion approach on coastal environments. Remote Sens., 5, 6880-6898, doi: 10.3390/rs5126880. [Link]

Nakano, T., I. Kamiya, M. Tobita, J. Iwahashi, and H. Nakajima, 2014: Landform monitoring in active volcano by UAV and SfM-MVS technique. Int. Arch. Photogramm. Remote Sens. Spatial Inf. Sci., XL-8, 71-75, doi: 10.5194/isprsarchives-XL-8-71-2014. [Link]

Niethammer, U., M. R. James, S. Rothmund, J. Travelletti, and M. Joswig, 2012: UAV-based remote sensing of the Super-Sauze landslide: Evaluation and results. Eng. Geol., 128, 2-11, doi: 10.1016/j.enggeo.2011.03.012. [Link]

Pajares, G., 2015: Overview and current status of remote sensing applications based on unmanned aerial vehicles (UAVs). Photogramm. Eng. Rem. Sens., 81, 281330, doi: 10.14358/PERS.81.4.281. [Link]

Quaritsch, M., K. Kruggl, D. Wischounig-Strucl, S. 
Bhattacharya, M. Shah, and B. Rinner, 2010: Networked UAVs as aerial sensor network for disaster management applications. $e$ \& $i$ Elektrotechnik und Informationstechnik, 127, 56-63, doi: 10.1007/s00502010-0717-2. [Link]

Rao, G., A. Lin, B. Yan, D. Jia, X. Wu, and Z. Ren, 2011: Co-seismic Riedel shear structures produced by the $2010 \mathrm{M}_{\mathrm{w}}$ 6.9 Yushu earthquake, central Tibetan Plateau, China. Tectonophysics, 507, 86-94, doi: 10.1016/j. tecto.2011.05.011. [Link]

Rizaldy, A. and W. Firdaus, 2012: Direct georeferencing: A new standard in photogrammetry for high accuracy mapping. Int.Arch. Photogramm. Remote Sens. Spatial Inf. Sci., XXXIX-B1, 5-9, doi: 10.5194/isprsarchivesXXXIX-B1-5-2012. [Link]

Rusnák, M., J. Sládek, A. Kidová, and M. Lehotský, 2018: Template for high-resolution river landscape mapping using UAV technology. Measurement, 115, 139-151, doi: 10.1016/j.measurement.2017.10.023. [Link]

Ryan, J. C., A. L. Hubbard, J. E. Box, J. Todd, P. Christoffersen, J. R. Carr, T. O. Holt, and N. Snooke, 2015: UAV photogrammetry and structure from motion to assess calving dynamics at Store Glacier, a large outlet draining the Greenland ice sheet. The Cryosphere, 9, 1-11, doi: 10.5194/tc-9-1-2015. [Link]

Saito, H., S. Uchiyama, Y. S. Hayakawa, and H. Obanawa, 2018: Landslides triggered by an earthquake and heavy rainfalls at Aso volcano, Japan, detected by UAS and SfM-MVS photogrammetry. Progress in Earth and Planetary Science, 5, doi: 10.1186/s40645-018-01696. [Link]

Shyu, J. B. H., K. Sieh, Y.-G. Chen, and C.-S. Liu, 2005: Neotectonic architecture of Taiwan and its implications for future large earthquakes. J. Geophys. Res., 110, doi: 10.1029/2004JB003251. [Link]

Shyu, J. B. H., Y. R. Chuang, Y. L. Chen, Y. R. Lee, and C. T. Cheng, 2016: A new on-land seismogenic structure source database from the Taiwan Earthquake Model (TEM) project for seismic hazard analysis of Taiwan. Terr. Atmos. Ocean. Sci., 27, 311-323, doi: 10.3319/ TAO.2015.11.27.02(TEM). [Link]

Smith, M. W. and D. Vericat, 2015: From experimental plots to experimental landscapes: Topography, erosion and deposition in sub-humid badlands from Structurefrom-Motion photogrammetry. Earth Surf. Process. Landf., 40, 1656-1671, doi: 10.1002/esp.3747. [Link]

Smith, M. W., J. L. Carrivick, and D. J. Quincey, 2016: Structure from motion photogrammetry in physical geography. Prog. Phys. Geogr., 40, 247-275, doi: 10.1177/0309133315615805. [Link]

Sylvester, A. G., 1988: Strike-slip faults. GSA Bull., 100, 1666-1703, doi: 10.1130/0016-7606(1988)100<1666: $\mathrm{SSF}>2.3 . \mathrm{CO} ; 2 .[\mathrm{Link}]$

Thiele, S. T., S. Micklethwaite, P. Bourke, M. Verrall, and P. Kovesi, 2015: Insights into the mechanics of en-échelon sigmoidal vein formation using ultra-high resolution photogrammetry and computed tomography. J. Struct. Geol., 77, 27-44, doi: 10.1016/j. jsg.2015.05.006. [Link]

Tonkin, T. N., N. G. Midgley, D. J. Graham, and J. C. Labadz, 2014: The potential of small unmanned aircraft systems and structure-from-motion for topographic surveys: A test of emerging integrated approaches at Cwm Idwal, North Wales. Geomorphology, 226, 3543, doi: 10.1016/j.geomorph.2014.07.021. [Link]

Uysal, M., A. S. Toprak, and N. Polat, 2015: DEM generation with UAV photogrammetry and accuracy analysis in Sahitler hill. Measurement, 73, 539-543, doi: 10.1016/j.measurement.2015.06.010. [Link]

Vollgger, S. A. and A. R. Cruden, 2016: Mapping folds and fractures in basement and cover rocks using UAV photogrammetry, Cape Liptrap and Cape Paterson, Victoria, Australia. J. Struct. Geol., 85, 168-187, doi: 10.1016/j.jsg.2016.02.012. [Link]

Wang, Y. J., C. H. Chan, Y. T. Lee, K. F. Ma, J. B. H. Shyu, R. J. Rau, and C. T. Cheng, 2016: Probabilistic seismic hazard assessment for Taiwan.Terr.Atmos.Ocean.Sci., 27, 325-340, doi: 10.3319/TAO.2016.05.03.01(TEM). [Link]

Watts, A. C., V. G. Ambrosia, and E. A. Hinkley, 2012: Unmanned aircraft systems in remote sensing and scientific research: Classification and considerations of use. Remote Sens., 4, 1671-1692, doi: 10.3390/rs4061671. [Link]

Westoby, M. J., J. Brasington, N. F. Glasser, M. J. Hambrey, and J. M. Reynolds, 2012: 'Structure-from-Motion' photogrammetry: A low-cost, effective tool for geoscience applications. Geomorphology, 179, 300-314, doi: 10.1016/j.geomorph.2012.08.021. [Link]

Yen, J. Y., C. H. Lu, C. P. Chang, A. J. Hooper, Y. H. Chang, W. T. Liang, T. Y. Chang, M. S. Lin, and K. S. Chen, 2011: Investigating active deformation in the northern Longitudinal Valley and City of Hualien in eastern Taiwan using persistent scatterer and small-baseline SAR interferometry. Terr. Atmos. Ocean. Sci., 22, 291-304, doi: 10.3319/TAO.2010.10.25.01(TT). [Link]

Yen, J. Y., C. H. Lu, R. J. Dorsey, H. Kuo-Chen, C. P. Chang, C. C. Wang, R. Y. Chuang, Y. T. Kuo, C. Y. Chiu, Y. H. Chang, F. Bovenga, and W. Y. Chang, 2018: Insights into seismogenic deformation during the 2018 Hualien, Taiwan, earthquake sequence from InSAR, GPS, and modeling. Seismol. Res. Lett., 90, 78-87, doi: 10.1785/0220180228. [Link]

Zachariasen, J. and K. Sieh, 1995: The transfer of slip between two en echelon strike-slip faults: A case study from the 1992 Landers earthquake, southern California. J. Geophys. Res., 100, 15281-15301, doi: 10.1029/95JB00918. [Link] 